\title{
Prediction of Pressing Quality for Press-Fit Assembly Based on Press-Fit Curve and Maximum Press-Mounting Force
}

\author{
Bo You, ${ }^{1}$ Zhifeng Lou, ${ }^{2}$ Yi Luo, ${ }^{1,2}$ Yang Xu, ${ }^{1}$ and Xiaodong Wang ${ }^{1,2}$ \\ ${ }^{1}$ Key Laboratory for Micro/Nano Technology and System of Liaoning Province, Dalian University of Technology, \\ Dalian, Liaoning 116023, China \\ ${ }^{2}$ Key Laboratory for Precision and Non-Traditional Machining of Ministry of Education, Dalian University of Technology, \\ Dalian, Liaoning 116023, China \\ Correspondence should be addressed to Xiaodong Wang; xdwang@dlut.edu.cn
}

Received 5 May 2015; Revised 14 June 2015; Accepted 18 June 2015

Academic Editor: Christopher J. Damaren

Copyright (C) 2015 Bo You et al. This is an open access article distributed under the Creative Commons Attribution License, which permits unrestricted use, distribution, and reproduction in any medium, provided the original work is properly cited.

In order to predict pressing quality of precision press-fit assembly, press-fit curves and maximum press-mounting force of pressfit assemblies were investigated by finite element analysis (FEA). The analysis was based on a 3D Solidworks model using the real dimensions of the microparts and the subsequent FEA model that was built using ANSYS Workbench. The press-fit process could thus be simulated on the basis of static structure analysis. To verify the FEA results, experiments were carried out using a press-mounting apparatus. The results show that the press-fit curves obtained by FEA agree closely with the curves obtained using the experimental method. In addition, the maximum press-mounting force calculated by FEA agrees with that obtained by the experimental method, with the maximum deviation being $4.6 \%$, a value that can be tolerated. The comparison shows that the press-fit curve and max press-mounting force calculated by FEA can be used for predicting the pressing quality during precision press-fit assembly.

\section{Introduction}

The pressing quality of press-fit assembly is extraordinarily important in all its application, especially in aviation and aerospace industry; thus, quality prediction is crucial. The pressing quality of press-fit assembly is related to not only the selection of interference value and diameter but also the press-fit process. However, it has until now been very difficult to predict the pressing quality of a press-fit assembly by a press-fit process analysis method.

In recent years, with the increasing sophistication of computers, FEA is being gradually applied to predict the press-fit quality by analyzing the press-fit process. Benuzzi and Donzella [1] presented a new method to predict pressfit curve. The accuracy of this method can satisfy precision requirements. In addition, the presented method is simpler than FEA method. However, it has its limitations as it can only be utilized in elastic field. Xiao et al. [2] developed a software to judge automatically whether press-fit curves of wheelsets are qualified or not, and it was demonstrated that the successful rate when using that software could reach $99.4 \%$. But it has two limitations. One is that it can only determine whether the press-fit curve is qualified or not, but it cannot predict the pressing quality of a press-fit assembly; the other is that it can only be utilized for determining the pressing quality of wheelsets. Zhao et al. [3] implemented numerical simulation and experimental research on knurl interference connection; the relationship between interference value and maximum transferred torque moment was studied; the results showed that the relationship obtained from FEA is similar to these results obtained from experiment. Although the reliability of FEA has been demonstrated, however, since the accuracy of the method is very low, it cannot satisfy the precision requirements of microparts assembly. Yu et al. [4] investigated the velocity-displacement curve for mechanical linkage of servo presses; according to the relationship between velocity and displacement of mechanical linkage, it could be validated that the technology scope of mechanical linkage servo presses was 
larger than that of traditional mechanical presses. In addition, mechanical linkage servo presses were more productive than traditional mechanical press. But the velocity-displacement curve can only be used in heavy mechanical servo presses. $\mathrm{Lu}$ et al. [5] studied the influence of the crank radius of mechanical linkage servo presses on displacement curves, velocity curves, and acceleration curves for high-speed precision press mounting by using an ADAMS software. The results showed that the velocity and acceleration would decrease with an increase of the crank radius at bottom dead center. The phenomenon was helpful in reducing torque consumption during high-speed precision press mounting. At the same time, the lateral force of the slider would be reduced with every increase of working angle. However, it can only be utilized for high-speed precision presses, rather than typical low-speed precision presses.

Press-fit curves can be divided into two categories, namely, the force-time curve and the force-displacement curve. Many researchers have investigated the influence of different kinds of press-fit curves on the pressing prediction. He and Jia [6] studied influence of the type of mechanical linkage on the stability of press mounting; they calculated the impact force according to inverse theory and then established the relationship between impact force and time; thereby force-time curves were obtained. Their results showed that triangle linkage is better than crank block linkage for mechanical presses. Hu et al. [7] calculated force-time curves by analyzing the working device mechanical structure of hydraulic excavator. According to force-time curves obtained from mechanical structure analysis, the load spectrum was controlled in order to reduce digging resistance. The advantages of that method were verified by practical application, fewer measured points, simpler measured procedures, and lower costs. It is not difficult to see that the method can only be used to control large hydraulic presses with complicated working device and not for low-speed high precision presses. The reason is that the working device of high-speed press should not be complicated. Sun and Kim [8] set virtual buttons on force-displacement curves to detect the frequency of corresponding positions. The practical frequency is established by haptic feedback. If force-displacement curve does not pass through these virtual buttons, the press will not be qualified. The results obtained by this method are realistic, but they are greatly influenced by environmental factors such as vibration, so it does not work for high precision presses. Zhao [9] developed a new method which can be utilized to judge whether a conveyor belt joint is damaged or not according to force-displacement curves. The method has a certain action, but its accuracy is not high for crack. You et al. [10] investigated the influence of contact algorithms including Pure Penalty algorithm, Augmented Lagrange algorithm, and Normal Lagrange algorithm on predicting press-fit curves. The results showed that Augmented Lagrange algorithm is the most effective. Haque et al. [11] studied the relationship between force-displacement curve and riveting process. They thought that if the process parameters did not change, the riveting quality could be judged according to the influence of the impact force on the force-displacement curve. The results showed that force-displacement curve could be used to monitor the riveting process and then to judge whether the riveting process was successful or not. But the method can only be used in situations with a great impact force. However, they are available in few literatures on predicting the pressing quality of press-fit assembly according to press-fit curve and maximum press-mounting force.

The purpose of this paper is to verify the accuracy of the press-fit curves and maximum press-mounting forces obtained from FEA by comparing them with experimental results, in order to determine whether press-fit curves and maximum press-mounting force that are established on the basis of the results obtained from FEA can be considered reasonably accurate and ultimately whether the pressing quality of a press-fit assembly can be judged according to these two indicators.

\section{Finite Element Analysis}

Electrohydraulic servo valve is a core component of electrohydraulic servo control system used regularly in aeronautic and aerospace field. It is composed of torque motor and fourway reversing valve [12]. Electrohydraulic servo valve can convert the weak electric signal into hydraulic power and thus the position, speed, or force can be controlled. The hydraulic power can be tens of horsepower. The press-fit micropart in this paper is a core component which is a bridge between the torque motor and four-way reversing valve.

Since the microparts are aerospace components assembled by press-fit assembly, the thin wall of the shaft will be deflected when both wings of hole are produced with deflection. Because the thin wall of the shaft is deflected, the spool of the four-way reversing valve will be moved. Thereby the oil pressure on the two sides of the spool will become different, and then the position, speed, or force can be controlled. Finally, the flight attitude of the flying vehicle can be corrected.

2.1. FEM Model Description. Since press-fit curve and maximum press-mounting force are important technical methods for predicting the pressing quality of any press-fit assembly, FEA was implemented in this paper to illustrate how the press-fit curve and maximum press-mounting force were changed in the press-fit process by using ANSYS Workbench. A series of press-fit curves with different interference values were obtained from the analysis. The rational range of pressfit curves can be obtained according to the press-fit curves mentioned above. At the same time, we can obtain the maximum press-mounting forces and their rational range by reading the values of press-fit curves. Finally, by comparing these calculated values with those obtained from an actual press-fit process, it could be determined whether the calculated values fell within a range of rational accuracy enough to allow for their practical application.

The geometric model is shown in Figure 1. The parts of the geometric model are made of two different materials, 3J1 and 1J50.3J1 is high elastic alloy having weak magnetic and corrosion. This kind of alloy possesses a lot of characteristics which include higher strength, higher Young's modulus, lower elastic hysteresis and weak magnetism, better corrosion 


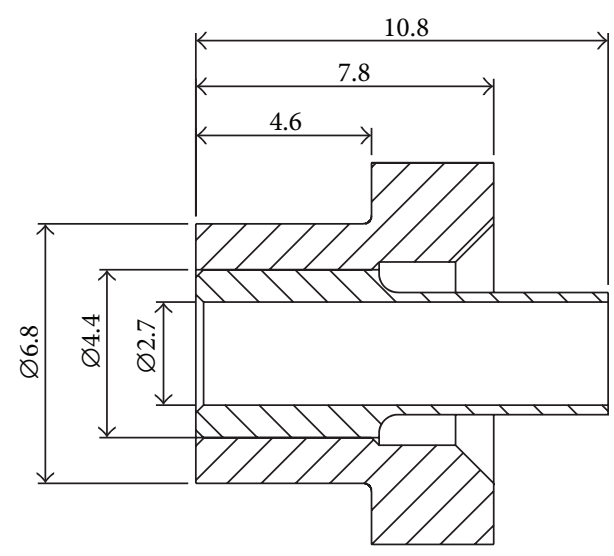

FIgURE 1: Geometric model (units: mm).

resistance, and thermal stability. So it can be applied for environment with higher temperature, larger stress, or corrosive medium. 1J50 is a soft magnetic alloy having high permeability and saturation magnetic induction. Since this kind of alloy has antirust property and processing performance, it can be applied for making components with sky-high form accuracy and dimensional precision. The saturation magnetic induction and curie temperature of 1J50 are higher than other soft magnetic alloys, so it is applied for making electronic components in aerospace industry.

Their mechanical properties are listed in Table 1. Because of the existence of plastic areas on the contact surface, a plastic model is adopted. The plastic model is bilinear isotropic hardening model. Tangential moduli are $942 \mathrm{MPa}$ and $1116 \mathrm{MPa}$, respectively.

Table 2 shows the stress-strain laws of materials mentioned above in their plastic zones. The tangential moduli are slopes of the stress-strain laws of materials in their plastic zones.

Load and boundary conditions are shown in Figure 2. A static structure analysis was carried out. The geometric model is axisymmetric. Table 3 demonstrates contact definition of the press-fit assembly. In fact, the setting of the interference value is achieved by setting up an offset value of the contact surface between two parts of press-fit assembly.

The value of 0.09 assumed for friction coefficient is a calculating value. The calculating method is shown as follows [13]:

$$
f=\tan \left(\cos ^{-1}\left(1-\frac{\sigma_{s}}{E}\right)\right),
$$

where $f$ is the value of friction coefficient, $\sigma_{s}$ is the material of yield strength (MPa), and $E$ is the material of Young's modulus (MPa).

According to $\sigma_{s}$ and $E$ of $3 J 1$ and 1J50, the friction coefficients of 3J1 and $1 J 50$ can be calculated by using (1). The friction coefficient of $3 \mathrm{~J} 1$ is 0.09 , while the friction coefficient of 1 J50 is 0.11 . So, the rational scope of friction coefficient is from 0.09 to 0.11 :

$$
F=\left(730.4 f+0.03 e^{-10}\right) \times 9.81,
$$

TABLE 1: Mechanical properties of 3J1 and 1J50.

\begin{tabular}{lcccc}
\hline Material & $\begin{array}{c}\text { Young's } \\
\text { modulus } \\
(\mathrm{MPa})\end{array}$ & $\begin{array}{c}\text { Poisson's } \\
\text { ratio }\end{array}$ & $\begin{array}{c}\text { Yield } \\
\text { strength } \\
(\mathrm{MPa})\end{array}$ & $\begin{array}{c}\text { Tangential } \\
\text { modulus } \\
(\mathrm{MPa})\end{array}$ \\
\hline $3 \mathrm{J1}$ & 157000 & 0.34 & 686 & 942 \\
$1 \mathrm{J50}$ & 186000 & 0.3 & 882 & 1116 \\
\hline
\end{tabular}

TABLE 2: Stress-strain laws of materials in plastic zone.

\begin{tabular}{lccc}
\hline $\begin{array}{l}\text { Stress (3J1) } \\
(\mathrm{MPa})\end{array}$ & Strain (3J1) & $\begin{array}{c}\text { Stress (1J50) } \\
(\mathrm{MPa})\end{array}$ & Strain (1J50) \\
\hline 690 & 0.00495 & 887 & 0.00615 \\
793 & 0.00989 & 946 & 0.01194 \\
844 & 0.01505 & 1004 & 0.01600 \\
895 & 0.02002 & 1061 & 0.02000 \\
942 & 0.02229 & 1116 & 0.02243 \\
\hline
\end{tabular}

TABLE 3: Contact definition.

\begin{tabular}{ll}
\hline Contact model & Surface to surface \\
\hline Type & Frictional \\
Coefficient of friction & 0.09 \\
Offset & Set manually \\
Behavior & Asymmetric \\
Formulation & Penalty function \\
Penetration tolerance & $0.5 \mu \mathrm{m}$ \\
(FTOLN) & CONTA 174 and \\
Element & TARGE 170 \\
\hline
\end{tabular}

where $F$ is the maximum value of press-mounting force $(\mathrm{N})$ and $f$ is the friction coefficient of material.

According to (2), the maximum value of press-mounting force can be calculated. The maximum press-mounting force can be tolerated when the assumed friction coefficient is 0.09 . So the value of friction coefficient is assumed as 0.09 .

$1 / 2$ finite element model meshed by hexahedral element is shown in Figure 3. The elements number is 119681. The nodes number is 27677 . The minimum element size is $0.0019 \mathrm{~mm}$. The maximum element size is $0.0038 \mathrm{~mm}$. The minimum edge length of element is $0.1 \mathrm{~mm}$.

2.2. Simulation Results. According to practical situations, when the interference value is less than $12 \mu \mathrm{m}$, the maximum press-mounting force will fall below the lower limit. The lower limit of the maximum press-mounting force is defined as the maximum press-mounting force when the interference value is minimum $(12 \mu \mathrm{m})$. The value of the lower limit is $700 \mathrm{~N}$ which is an empirical value according to the pressmounting experiments. And when the interference value is greater than $14 \mu \mathrm{m}$, an extremely large plastic deformation will appear on the contact surface and inside of hollow shaft. The equivalent stress of microparts is shown in Figure 4. 


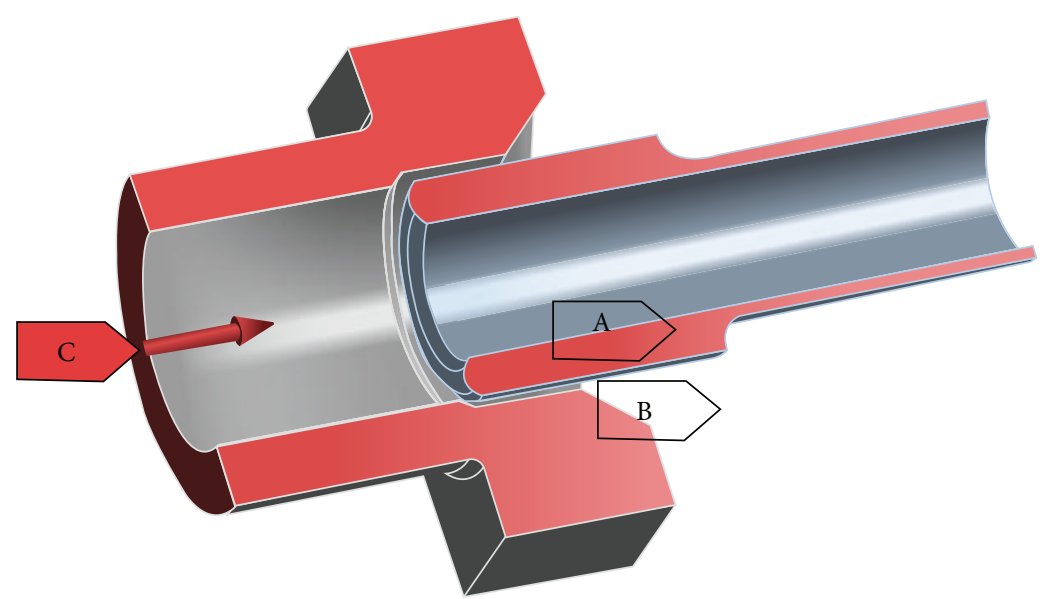

A: static structural

displacement

Time: $1 \mathrm{~s}$

2014/9/17 20:27

A Symmetry: Plane 5

B Frictionless support

C Displacement: $-4.8 \mathrm{~mm}$

FIGURE 2: Load and boundary conditions.

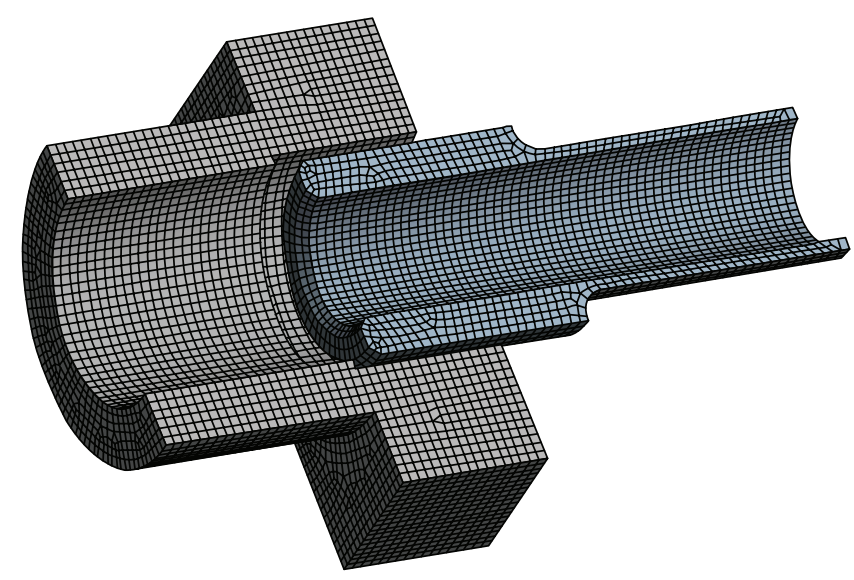

FIgURE 3: Finite element method model of 1/2 microparts.
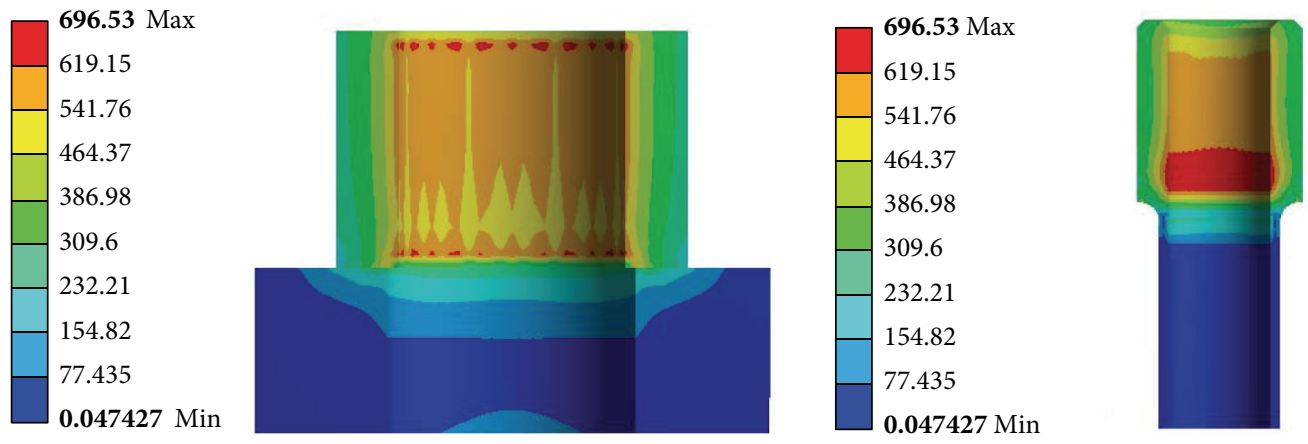

FIGURE 4: The equivalent stress of microparts. 
TABLE 4: Maximum press-mounting force obtained from FEA.

\begin{tabular}{lccc}
\hline $\begin{array}{l}\text { Interference value } \\
(\mu \mathrm{m})\end{array}$ & 12 & 13 & 14 \\
\hline $\begin{array}{l}\text { Maximum } \\
\text { press-mounting } \\
\text { force }(\mathrm{N})\end{array}$ & 715.895 & 769.506 & 828.621 \\
\hline
\end{tabular}

The simulation of press-fit assembly is based on the parameters above. Press-fit curves and maximum pressmounting force for a hollow shaft press-fit assembly with different interference values were obtained from FEA. These results are given in Figure 5 and Table 4.

The fluctuation can be explained as follows. At the beginning of press-fit assembly stage, the two microparts did not contact with each other. So the press-mounting force was 0 . However, when these two microparts contacted with each other, the press-mounting force can be increased suddenly to dozens of force.

According to the practical situation of press-fit assembly, the micropart transits noncontact state to contact state, and the press-mounting force changes suddenly from 0 to a certain value. The substeps were increased for obtaining the fluctuation of a press-fit curve. Four kinds of substeps were considered, which included 30 substeps, 50 substeps, 80 substeps, and 100 substeps. The fluctuation of the beginning of press-fit curve agrees well with the practical situation when the number of substeps is 100 . In addition, the slope of the fluctuation is nearly uniform when the number of substeps is more than 100.

Since the analysis of the press-fit process is nonlinear and uniform, the nonlinear large deformation option and step-bystep loading option are selected. In the beginning of the pressfit process, the press-mounting force would change suddenly, so more data is required to be collected. There were 130 iterations in the whole simulation of press-fit process. That meant dividing the $4.8 \mathrm{~mm}$ displacement into 13 steps, each of which had to be subdivided into 10 steps. The calculated results are shown in Figure 5, in which it can be seen that the maximum press-mounting force is the maximum value of the curve.

\section{Experimental Tests}

3.1. Experimental Design. According to FEA results and press-mounting precision requirements, a press-mounting apparatus was developed for assembling microparts. The apparatus consists of two functional modules: pressing module and parts alignment module. The pressing module is applied for assembling armature components, which includes grating ruler, guide shaft, straight push road, force sensor, moving beam, $X Y$ displacement platform, lower fixture, and upper fixture. The parts alignment module is machine vision device, which is applied for aligning parts.

The machine vision device was responsible for images acquisition of two parts to be pressed. In the press-mounting process, displacement and the press-mounting force were recorded by grating ruler and a force sensor, respectively. According to the records mentioned above, the press-fit

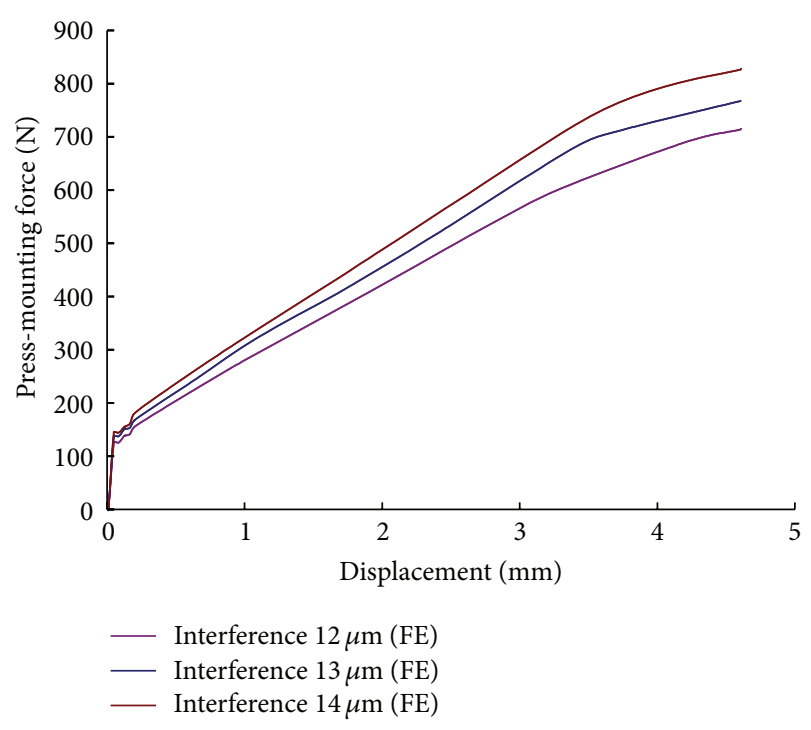

Figure 5: Press-fit curves obtained from FEA.

curves were drawn by control software. The device is shown in Figure 6.

In order to validate the accuracy of press-fit curves and maximum press-mounting forces obtained from FEA, a series of experimental tests were implemented on the pressmounting device. 18 samples were prepared for the series of experiments. Their shape errors and surface roughness were approximately identical. Table 5 shows the interference values of samples.

In the press-mounting process of the microparts, the press-mounting force is measured by force sensor which is installed on optics platform and connected with the bottom lower beam. The lower beam is located in floating status through coordinating with guide shaft and linear bearings. Thereby the press-mounting force can be fully applied on force sensor. And then the accuracy of measurement can be guaranteed. The type of the force sensor is BK-6C which was produced by China Academy of Aerospace Aerodynamics. The scheme of measuring press-mounting force is shown in Figure 7.

The displacement is measured by the grating ruler. The grating reading head is fixed on the moving beam. Crust of the grating ruler is installed on aluminum alloy section. The bottom of aluminum alloy section is fixed on the lower beam. Since the upper beam can be deformed by the pressmounting force, the top of aluminum alloy section is jointed with the upper beam by guide frame which is composed of aluminum alloy section; thereby, the top of aluminum alloy section is located in floating status, and then the accuracy of measurement can be guaranteed. The type of the grating ruler is KA-300. The scheme of measuring displacement is shown in Figure 8.

3.2. Experimental Results. The press-fit curves and maximum press-mounting forces of microparts with different interference values were obtained from the experiments. These results are given in Figure 9 and Table 6. 


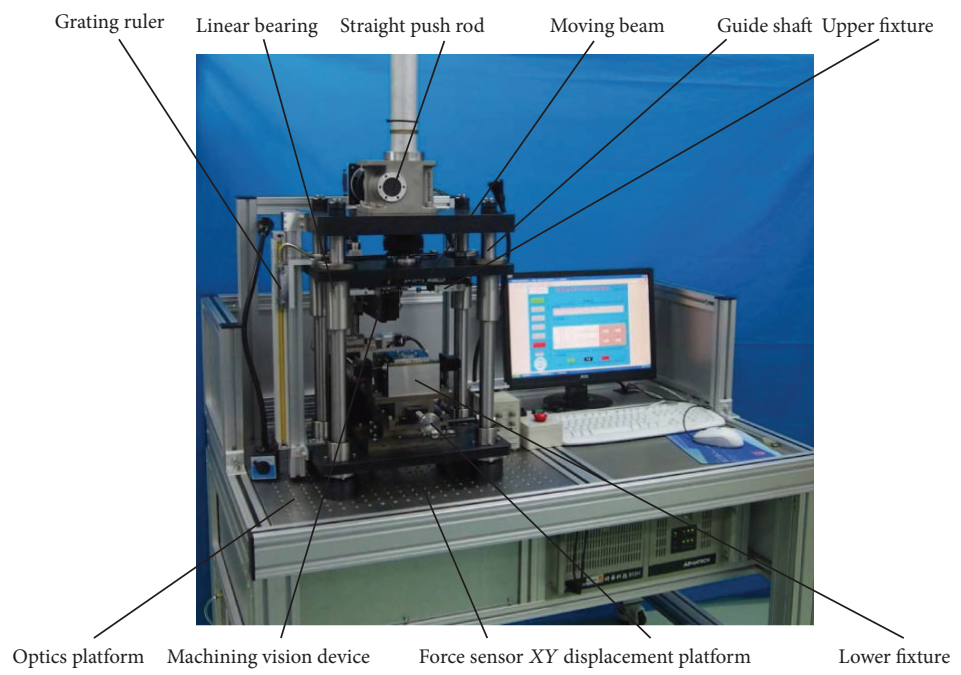

FIgURE 6: The press-mounting apparatus.

TABLE 5: Interference values of samples.

\begin{tabular}{lccc}
\hline Number & $\begin{array}{c}\text { Interference } \\
\text { value }(\mu \mathrm{m})\end{array}$ & Number & $\begin{array}{c}\text { Interference } \\
\text { value }(\mu \mathrm{m})\end{array}$ \\
\hline Sample 1 & 12 & Sample 10 & 14 \\
Sample 2 & 12 & Sample 11 & 14 \\
Sample 3 & 14 & Sample 12 & 14 \\
Sample 4 & 13 & Sample 13 & 12 \\
Sample 5 & 12 & Sample 14 & 13 \\
Sample 6 & 13 & Sample 15 & 13 \\
Sample 7 & 13 & Sample 16 & 12 \\
Sample 8 & 13 & Sample 17 & 14 \\
Sample 9 & 12 & Sample 18 & 14 \\
\hline
\end{tabular}

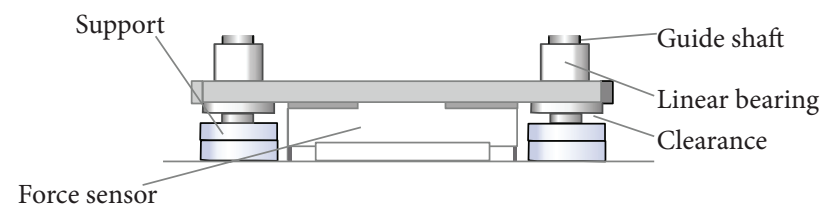

FIGURE 7: The press-mounting apparatus.

The mean values of maximum press-mounting force with the same interference value were calculated. The results are listed in Table 7.

The standard deviations of maximum press-mounting forces with different interference values were calculated for evaluating dispersion degree of the maximum pressmounting forces with different interference values. The calculating method is shown in

$$
\sigma=\sqrt{\frac{1}{N} \sum_{i=1}^{N}\left(x_{i}-\mu\right)^{2}},
$$

TABLE 6: Maximum press-mounting forces obtained from experiments.

\begin{tabular}{lccc}
\hline Number & $\begin{array}{c}\text { Maximum } \\
\text { press-mounting } \\
\text { force (N) }\end{array}$ & Number & $\begin{array}{c}\text { Maximum } \\
\text { press-mounting } \\
\text { force (N) }\end{array}$ \\
\hline Sample 1 & 726.381 & Sample 10 & 840.496 \\
Sample 2 & 721.369 & Sample 11 & 863.086 \\
Sample 3 & 890.297 & Sample 12 & 882.399 \\
Sample 4 & 771.017 & Sample 13 & 746.021 \\
Sample 5 & 744.942 & Sample 14 & 784.168 \\
Sample 6 & 795.316 & Sample 15 & 805.081 \\
Sample 7 & 783.760 & Sample 16 & 741.121 \\
Sample 8 & 789.793 & Sample 17 & 875.797 \\
Sample 9 & 760.696 & Sample 18 & 875.669 \\
\hline
\end{tabular}

TABLE 7: Mean values of maximum press-mounting forces.

\begin{tabular}{lccc}
\hline $\begin{array}{l}\text { Interference value } \\
(\mu \mathrm{m})\end{array}$ & 12 & 13 & 14 \\
\hline $\begin{array}{l}\text { Maximum } \\
\text { press-mounting force } \\
(\mathrm{N})\end{array}$ & 740.088 & 788.189 & 866.791 \\
\hline
\end{tabular}

where $\sigma$ is the standard deviation of maximum pressmounting force, $N$ is the number of maximum pressmounting forces, $x_{i}$ is the maximum press-mounting force, and $\mu$ is the mean value of maximum press-mounting forces.

According to (3), the standard deviations of the maximum press-mounting forces with different interference values can be calculated. The calculated results are listed in Table 8.

It is not difficult to see that the ratio of maximum pressmounting forces within the scope of mean value $1.96 \sigma$ is more than $95 \%$. The phenomenon shows that maximum press-mounting forces with the same interference value obey 


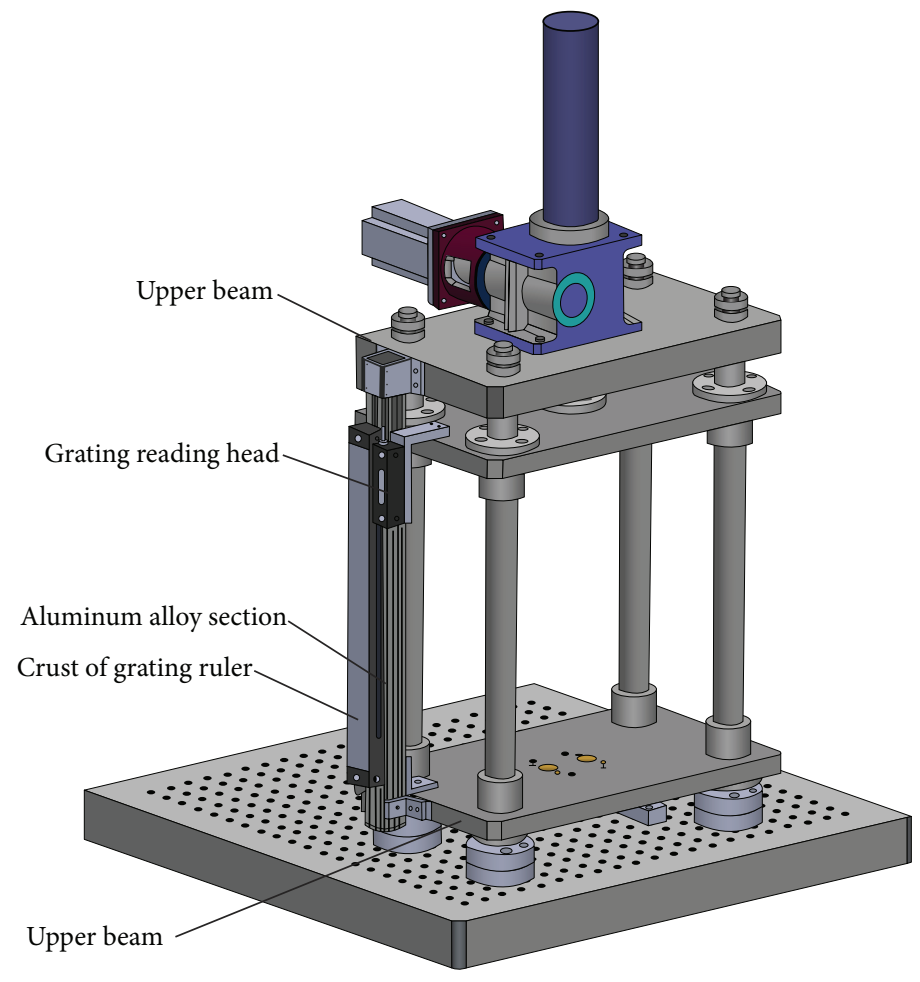

FIGURE 8: The scheme of measuring displacement.
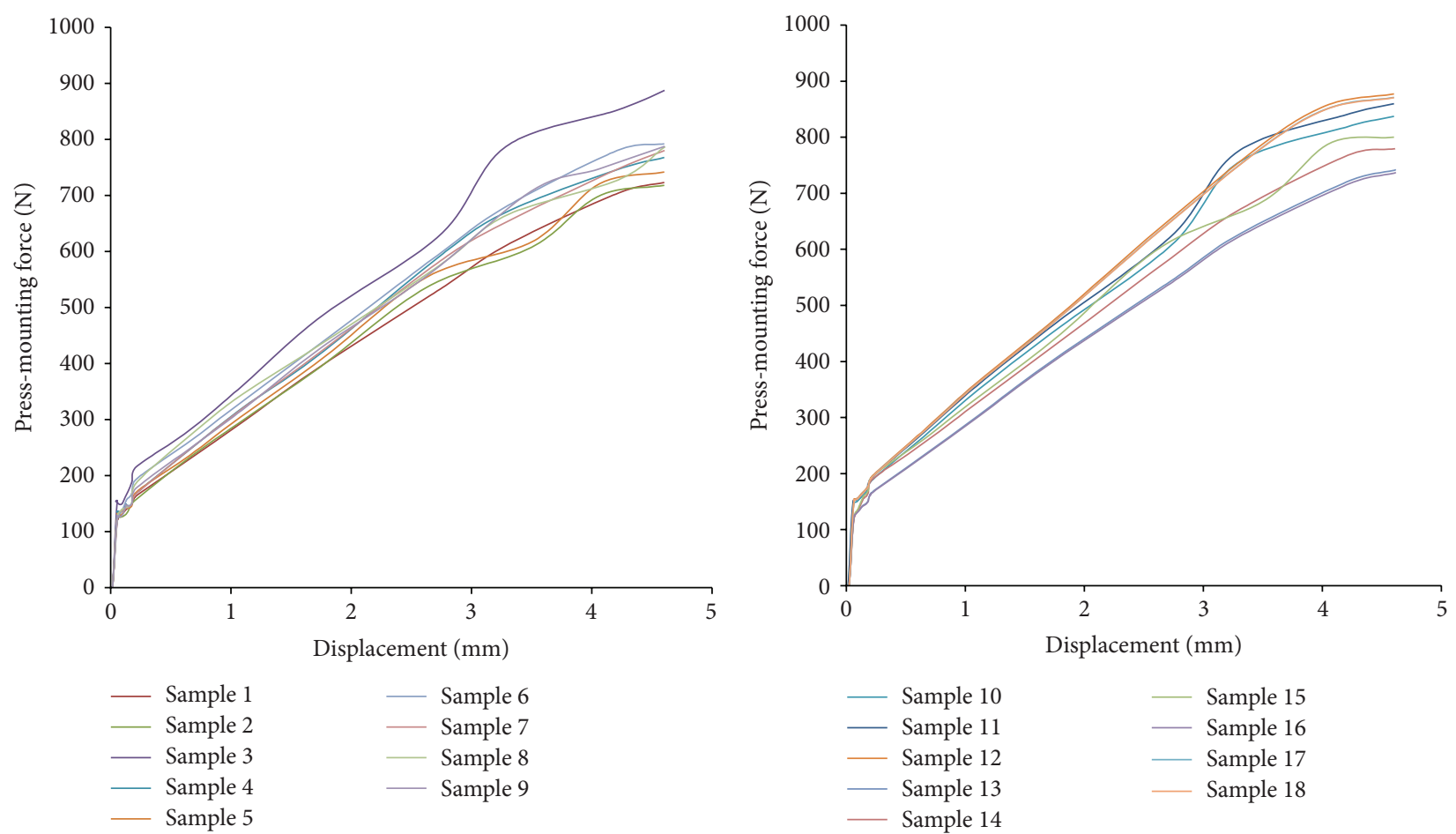

FIGURE 9: Press-fit curves obtained from the experiments. 
TABLE 8: Standard deviations of maximum press-mounting forces.

\begin{tabular}{lccc}
\hline $\begin{array}{l}\text { Interference value } \\
(\mu \mathrm{m})\end{array}$ & 12 & 13 & 14 \\
\hline $\begin{array}{l}\text { Standard deviation } \\
(\mathrm{N})\end{array}$ & 14.302 & 11.570 & 15.290 \\
\hline
\end{tabular}

normal distribution [14]. It means that the mean value of maximum press-mounting forces can be applied for representing the overall level of the maximum press-mounting forces with the same interference value.

On the basis of analyses mentioned above, the influence of interference value on the maximum press-mounting force is more significant than other factors (e.g., form error and surface roughness) by comparing maximum press-mounting forces with different interference values.

In the real press-mounting process, the value of the pressmounting force was collected once every $30 \mathrm{~ms}$, and then according to the relationship between press-mounting force and displacement, these curves can be drawn. It is found that these curves are not smooth due to the existence of surface roughness on the contact surface. In addition, due to the existence of cylindrical errors on the whole contact surfaces, the press-mounting force would change suddenly within a small range. The maximum press-mounting force can be obtained by reading the last value of the press-fit curve. The last value of the press-fit curve is the maximum value of the press-fit curve. The maximum press-mounting forces in Table 6 were both obtained by using this method.

\section{Results and Discussion}

As shown in Figure 10, the press-fit curves obtained from FEA and those obtained experimentally are put into the same figure. The dotted lines represent experimental results, and the real lines represent numerical results. The experimental results are mean values of samples which have the same interference value. Due to the existence of surface roughness, cylindrical error, and surface drawback, there are deviations between the press-fit curves obtained from FEA and experiments. But the trends of these press-fit curves are basically uniform.

The press-mounting process is divided into three stages, namely, initial stage, stable stage, and final stage. Since the micropart transits from noncontact state to contact state, the press-mounting force changes suddenly transiting in the initial stage from 0 to a certain value. In the stable stage, the press-mounting force is increased with increasing of the displacement. The increase mentioned above is close to linearity. In the end stage, the increment of the pressmounting force will be decreased, since elastic deformation is generated on the end of the contact surface. According to the analysis mentioned above, the numerical and experimental press-fit curves follow a reasonable course.

As shown in Table 9, the experimental results are mean values of samples which have the same interference value. Under the circumstances mentioned above, the deviations between numerical and experimental results can be
TABLE 9: Comparison among maximum press-mounting forces.

\begin{tabular}{lccc}
\hline $\begin{array}{l}\text { Interference } \\
\text { value }(\mu \mathrm{m})\end{array}$ & $\begin{array}{c}\text { Experimental } \\
\text { results }(\mathrm{N})\end{array}$ & $\begin{array}{c}\text { Simulating } \\
\text { results }(\mathrm{N})\end{array}$ & Deviation \\
\hline 12 & 740.088 & 715.895 & $3.3 \%$ \\
13 & 788.189 & 769.506 & $2.5 \%$ \\
14 & 866.791 & 828.621 & $4.6 \%$ \\
\hline
\end{tabular}

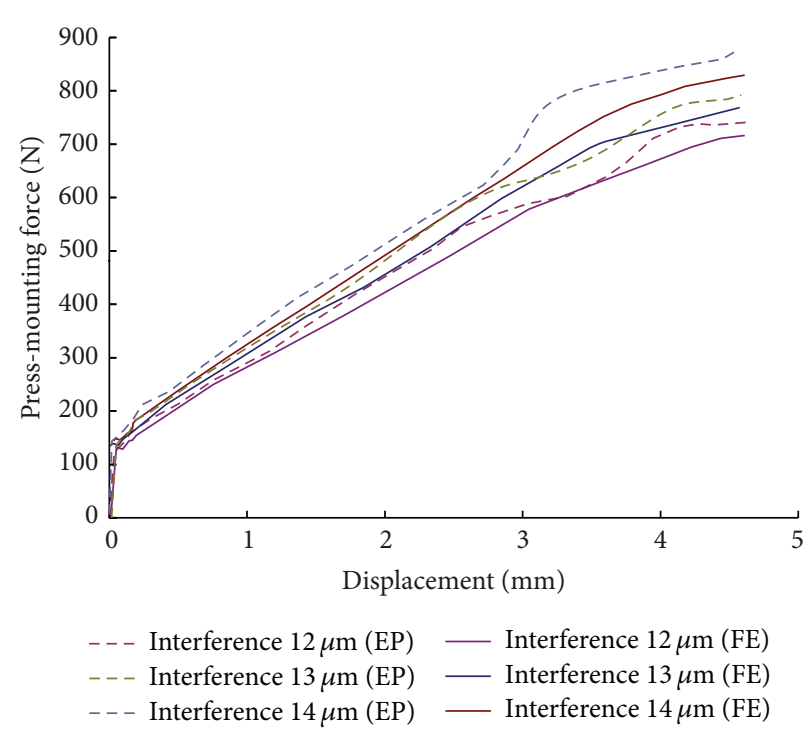

Figure 10: Comparison of the press-fit curves.

accepted according to practical situations. Therefore, the press-mounting force obtained from FEA can be used for evaluating the pressing quality of press-fit assembly.

According to our analysis, the pressing quality of microparts is determined by the shape of the press-fit curve and by the maximum press-mounting force. Therefore, as long as the gradient of the press-fit curve does not change significantly and the maximum press-mounting force falls within the range from $715.895 \mathrm{~N}$ to $828.621 \mathrm{~N}$, the pressing quality of microparts assembly is qualified.

\section{Conclusions}

The simulation of press-fit process was investigated with several interference values, and the pressing quality prediction of press-fit assembly was investigated by press-fit curve and maximum press-mounting force. According to the results, it was found that the FEA method could be applied for predicting the quality of press-fit assemblies. The corresponding conclusions can be drawn as follows:

(1) The press-fit curves obtained from FEA can be used to predict the pressing quality of microparts assembly according to the rational ranges of press-fit curves which are consistent with practical situations basically. In this paper, the rational range of press-fit curves is between a $12 \mu \mathrm{m}$ press-fit curve and a $14 \mu \mathrm{m}$ press-fit curve. 
(2) Once press-fit curves are obtained, the maximum press-mounting forces can be obtained by reading the maximum value of press-fit curves. If the maximum value is in the rational scope of maximum pressmounting force, the press-fit assembly is considered successful. The rational scope of maximum pressmounting force is from $715.895 \mathrm{~N}$ to $828.621 \mathrm{~N}$. The rational scope was obtained from numerical simulation of press-fit assembly, which was validated by using press-mounting experiments.

(3) The standard to judge the quality of the press-fit curve includes two factors which are the press-mounting force and the gradient of the press-fit curve. The pressmounting force data on the press-fit curve should be in the rational range of maximum press-mounting force. The rational range of the maximum pressmounting force is from $715.895 \mathrm{~N}$ to $828.621 \mathrm{~N}$. From the gradient of press-fit curve, there should be a fluctuation in the beginning of the press-fit curve. The press-mounting force should be nearly proportional to the increase of the displacement in the stable stage. In the end stage, the increment of the press-mounting force should be decreased. There are three kinds of unqualified press-fit curves in Figures 11, 12, and 13, respectively.

There is no contact in the initial pressing stage of the unqualified press-fit curve 1, but once shaft and hole are in contact, the press-mounting force changes suddenly. It can be noted that the gradient of the unqualified press-fit curve 1 is higher than that of the qualified press-fit curves throughout the whole pressing stage. Additionally, the maximum pressmounting force shown in curve 1 is higher than the upper limit $(828.621 \mathrm{~N})$. The above discussions indicate that the hole is tilted by the operator, which results in a certain angle between the top surface of the hole and the pressing surface. The unqualified press-fit curve 1 is shown in Figure 11.

The gradient of unqualified press-fit curve 2 is equal to qualified press-fit curves in the whole pressing stage, but its press-mounting forces exceed the upper limit at each point. At the same time, the equivalent stress is nearly equal to the yield limit, since a bilinear isotropic hardening model is applied. However, the area of plastic deformation exceeds the acceptable range. This means that the interference is too great. The unqualified press-fit curve 2 is shown in Figure 12.

The gradient of unqualified press-fit curve 3 is too high in the first half section. The above sign indicates that there is a conical shape error in the first half section of shafts press-fit surface. The press-mounting force of the first half pressing section is more than the upper limit, since the value of the conical shape error exceeds $2 \mu \mathrm{m}$. In the second half of the pressing section, interference is larger than $14 \mu \mathrm{m}$, as shown in unqualified press-fit curve 3 . The unqualified pressfit curve 3 is shown in Figure 13.

As mentioned above, FEA can be applied in simulation of the press-fit process to get press-fit curves, and then the rational range of press-fit curves is obtained according to the results obtained from FEA. According to the range, it can be confirmed whether press-fit assembly is successful

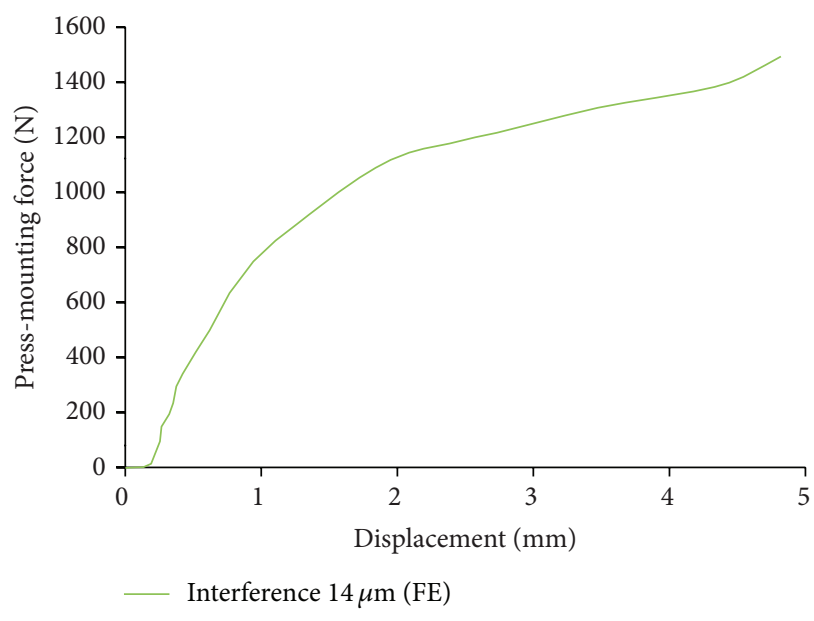

FIGURE 11: The unqualified press-fit curve 1.

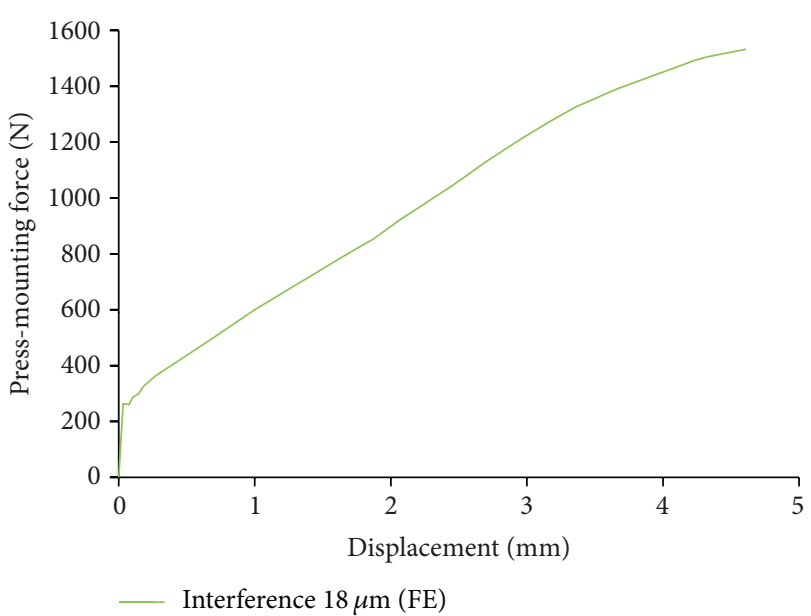

FIgURE 12: The unqualified press-fit curve 2.

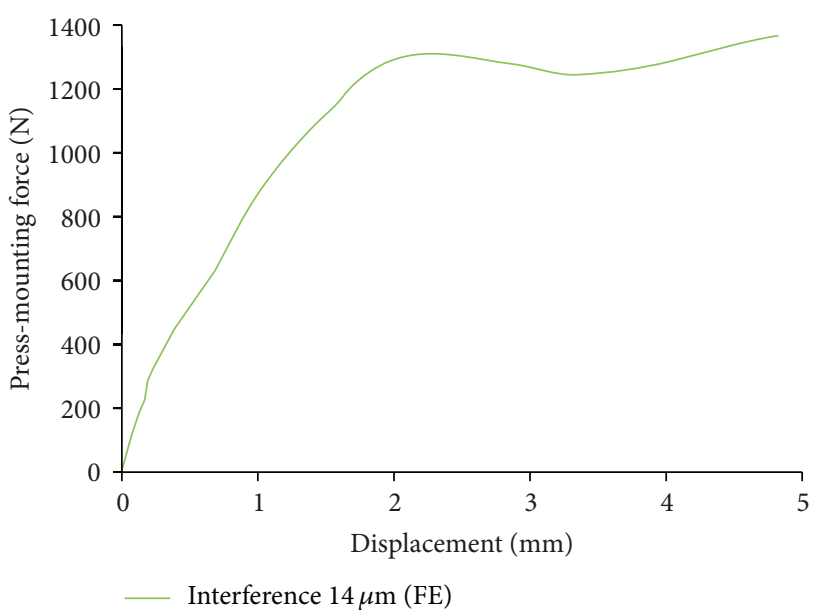

Figure 13: The unqualified press-fit curve 3. 
or not. Thereby, all the above work on press-fit assemblies makes further investigations of press-fit curves gradient for analyzing the pressing quality of press-fit assembly possible. Furthermore, it is the final purpose to infer the pressmounting failure causes according to the gradients of press-fit curves and the varieties of maximum press-mounting forces.

\section{Conflict of Interests}

The authors declare that there is no conflict of interests regarding the publication of this paper.

\section{Acknowledgments}

This project is supported by the National Nature Science Foundation of China (no. 51075058) and the Fundamental Research Funds for the Central Universities (DUT10ZDG04).

\section{References}

[1] D. Benuzzi and G. Donzella, "Prediction of the press-fit curve in the assembly of a railway axle and wheel," Journal of Rail and Rapid Transit, vol. 218, no. 1, pp. 51-65, 2004.

[2] J. Xiao, J. B. Han, X. Cheng, and R. Fang, "Research on automatic judgement of wheelset press-fit curve," Applied Mechanics and Materials, vol. 236-237, no. 1, pp. 1321-1326, 2012.

[3] J. J. Zhao, Z. J. Lu, and S. H. Xie, "Numerical simulation and test research on knurl interference connection," Advanced Materials Research, vol. 619, no. 3, pp. 207-212, 2013.

[4] J. Yu, L. C. Zhang, Y. S. Shi, H. Y. Xiong, and Z. Zhao, "Research on velocity-displacement curve for mechanical linkage servo press," Applied Mechanics and Materials, vol. 446-447, pp. 678682, 2014

[5] X. J. Lu, S. H. Zhu, Z. M. Ke, J. Qin, and S. Wei, "Influence of crank radius on the curve shapes for a multi-link high-speed precision press," Applied Mechanics and Materials, vol. 141, no. 1, pp. 313-318, 2012.

[6] P. He and F. Jia, "Reconstruction of impact force of mechanical press in time domain," Journal of Southeast University, vol. 27, no. 4, pp. 400-404, 2011.

[7] X. L. Hu, Q. Xiang, H. Zhang, G. Zhao, and L. Guo, "Research on calculation and measurement method of hydraulic excavator load force-time process," Applied Mechanics and Materials, vol. 401-403, no. 1, pp. 1091-1094, 2013.

[8] J. Sun and L. Kim, "Feedback design for a virtual button along force displacement curves," in Proceedings of the ACM Symposium on User Interface Software and Technology (UIST '13), pp. 91-96, St Andrews, UK, October 2013.

[9] W. Zhao, "Study on the steel cord belt joint monitoring based on force displacement curve," Applied Mechanics and Materials, vol. 443, no. 1, pp. 155-159, 2014.

[10] B. You, Y. Luo, and X. Wang, "Contact algorithm of Finite Element analysis for prediction of press-fit curve," Journal of Information and Computational Science, vol. 10, no. 9, pp. 25912600, 2013.

[11] R. Haque, J. H. Beynon, and Y. Durandet, "Characterisation of force-displacement curve in self-pierce riveting," Science and Technology of Welding and Joining, vol. 17, no. 6, pp. 476-488, 2012.
[12] G. R. Ren, Z. H. Zhang, and Y. Q. Zhou, Manufacturing Process of Electro-Hydraulic Servo Valve, China Astronautic Publishing House Press, Beijing, China, 1988.

[13] Z.X. Li, "Determination of the sliding friction factor by formula calculation," Lubrication Engineering, vol. 1, no. 5, pp. 18-20, 1999.

[14] J. Zhang, Mathematical Statistics, Science Press, Beijing, China, 2013. 

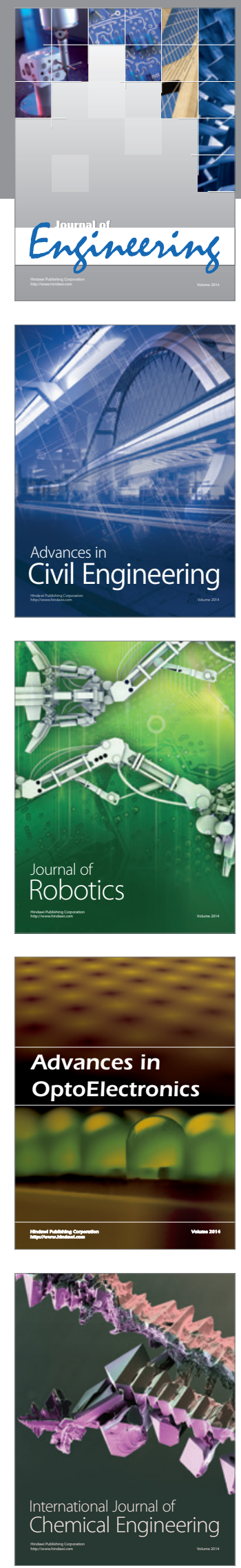

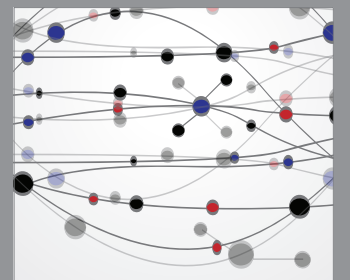

The Scientific World Journal
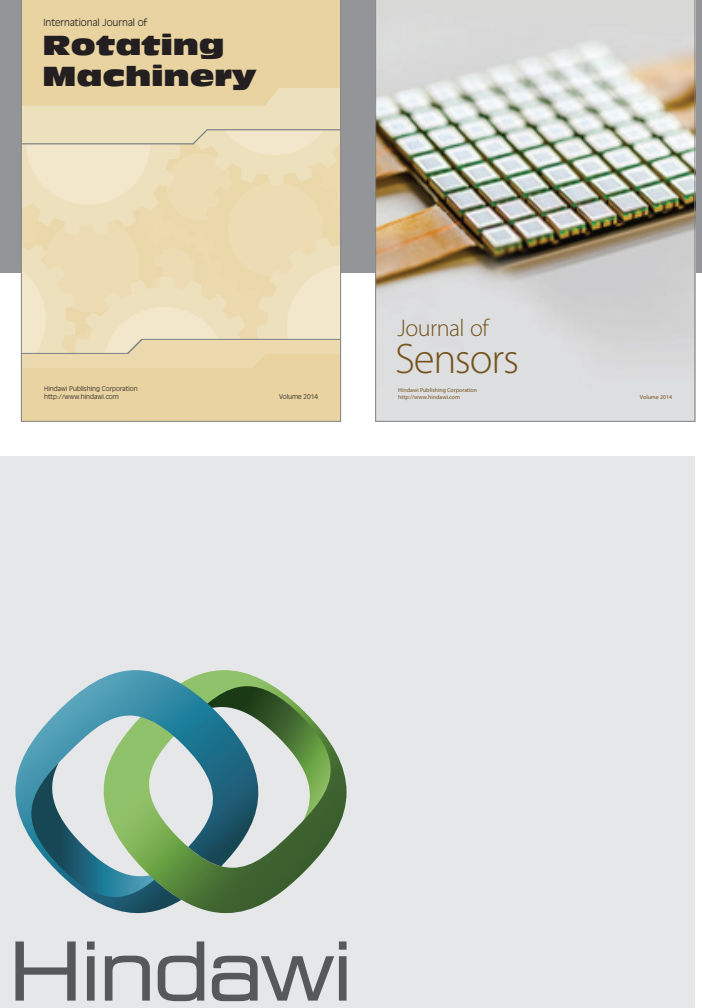

Submit your manuscripts at http://www.hindawi.com
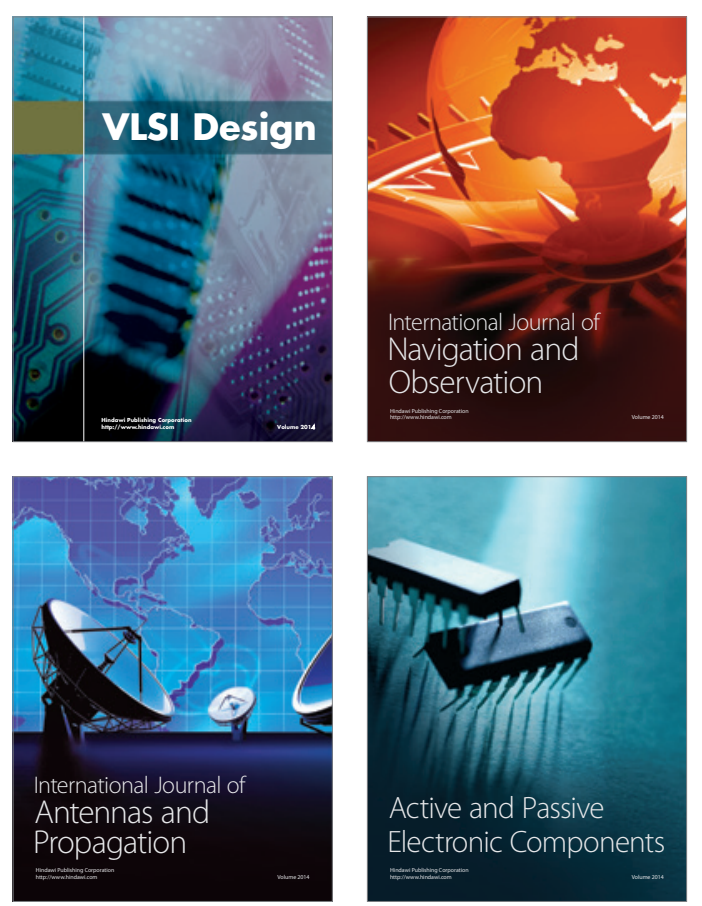
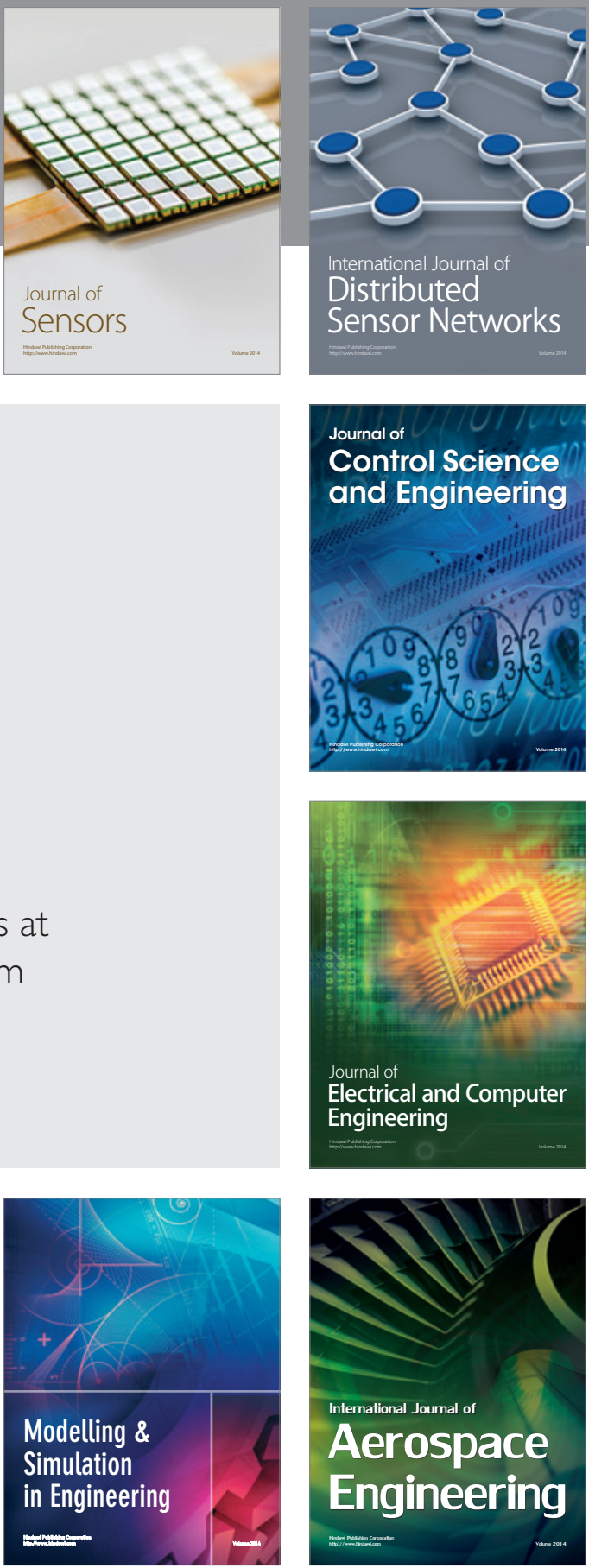

Journal of

Control Science

and Engineering
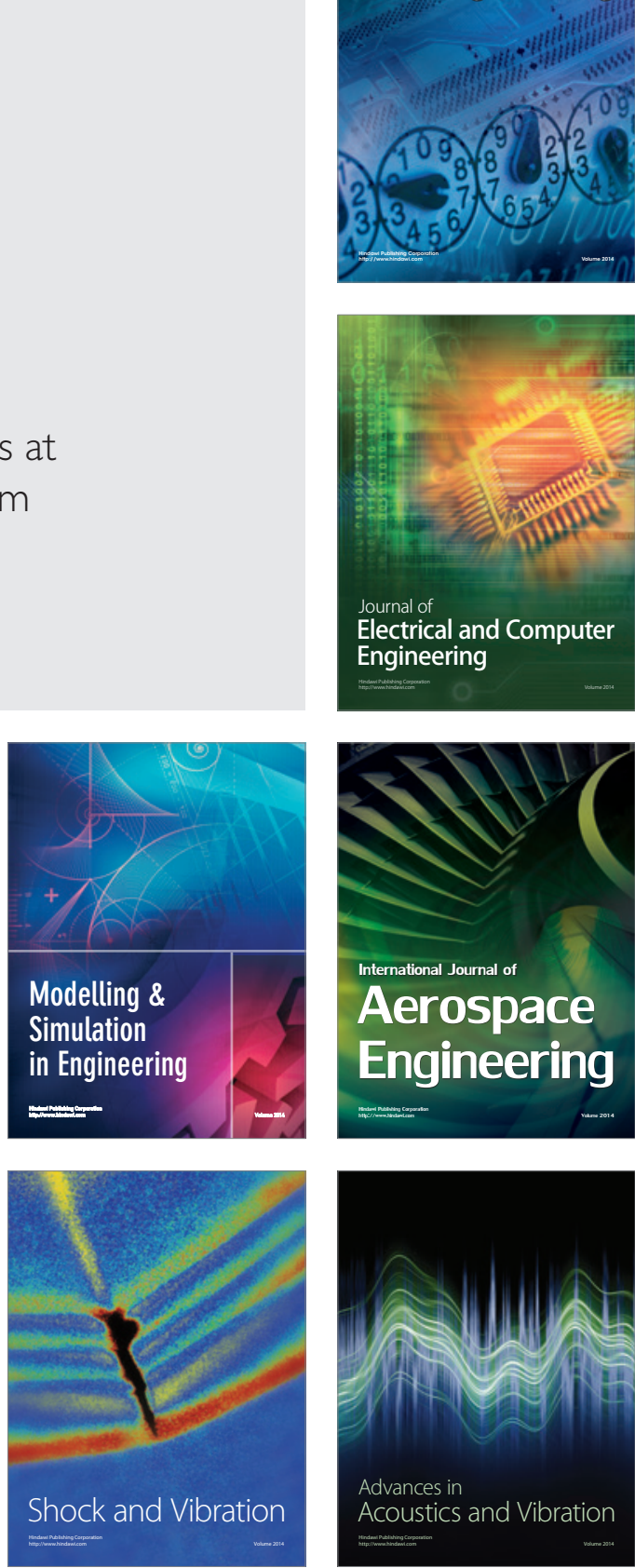